九州大学学術情報リポジトリ

Kyushu University Institutional Repository

\title{
Development and Sex Ratio of the Parasitoid Chrysocharis pentheus (Hymenoptera: Eulophidae) on the Leafminer Liriomyza trifolii (Diptera: Agromyzidae)
}

Sasaki, Fumi

Graduate School of Bioresource and Bioenvironmental Sciences, Kyushu University

Ueno, Takatoshi

Laboratory of Insect Natural Enemies, Division of Biological Control, Department of Applied Genetics and Pest Management, Faculty of Agriculture, Kyushu University

https://doi.org/10.5109/1564094

出版情報：九州大学大学院農学研究院紀要. 61 (1)，pp.133-139，2016-02-29. Faculty of Agriculture, Kyushu University

バージョン：

権利関係 : 


\title{
Development and Sex Ratio of the Parasitoid Chrysocharis pentheus (Hymenoptera: Eulophidae) on the Leafminer Liriomyza trifolii (Diptera: Agromyzidae)
}

\section{Fumi SASAKI ${ }^{1}$ and Takatoshi UENO*}

\author{
Laboratory of Insect Natural Enemies, Division of Biological Control, Department of Applied Genetics \\ and Pest Management, Faculty of Agriculture, Kyushu University, Fukuoka, 812-8581, Japan \\ (Received November 13, 2015 and accepted November 19, 2015)
}

\begin{abstract}
Leafmining flies such as Liriomyza trifolii and L. sativae are serious invasive pests of many agricultural and ornamental crops. Biological control with native parasitoids can be a promising approach to manage the leafminers. The larval parasitoid Chrysocharis pentheus is a common and widespread native natural enemy of Liriomyza spp. in Asia but many aspects of its biology remain unclear. Here, the laboratory culture of $C$. pentheus with $L$. trifolii was established and its development on the host was investigated. The percentage of parasitized hosts producing the parasitoid offspring was nearly $90 \%$ at $25^{\circ} \mathrm{C}$. Under low temperature/short day conditions, C. pentheus developed normally though the offspring survival was lower than that under $25^{\circ} \mathrm{C}$ conditions. Host $3^{\text {rd }}$ and $2^{\text {nd }}$ instars produced the parasitoid offspring with an equal proportion. However, the percentages of female parasitoids emerging from host 3rd instars were much higher than 2 nd instars. Curiously, the offspring sex ratio (\% females) was low at $15^{\circ} \mathrm{C}$. The female offspring took longer time to finish development than males did. The offspring parasitoids were larger when emerged from host third instars than second instars. Overall, the biology of $C$. pentheus is similar to other eulophid parasitoids attacking dipteran leafminers but our results suggest that $C$. pentheus is useful as a biocontrol agent during low temperature conditions.
\end{abstract}

Key words: Biocontrol, host quality, host selection, idiobiont, IPM, sex allocation

\section{INTRODUCTION}

Leafminers in the genus of Liriomyza (Agromyzidae) contain several worldwide notorious pests of agricultural and ornamental crops (Minkenberg and van Lenteren, 1986; Spencer, 1989; Liu et al., 2009; Foba et al., 2015). However, the management of Liriomyza spp. is often difficult solely with synthetic insecticides because they have developed high level of resistance (Wardlow, 1985; Parrella, 1987; Weintraub and Horowitz, 1998; Ohno et al., 1999a, b; Weintraub, 2001; Ueno, 2006; Matsuda and Saito, 2014; Saryazdi et al., 2014; Guantai et al., 2015).

In the field, Liriomyza spp. in the larval and pupal stages commonly suffer from a high level of parasitism by hymenopteran parasitoids (Rauf et al., 2000; Gratton and Welter, 2001; Salvo et al., 2005; Saito et al., 2008a; Liu et al., 2009; Foba et al., 2015). This fact leads to an idea that biological control with such parasitoids can work well. Indeed, parasitoids have proven successful as an agent of biological control of Liriomyza spp. (Minkenberg and van Lenteren, 1986; Parrella et al., 1987; Ozawa et al., 1998, 1999, 2001; Weintraub, 2001; Chow and Heinz, 2006; Liu et al., 2009).

In Japan, the community of leafminer parasitoids is rich, containing a variety of species that are native to the country (Arakaki and Kinjyo, 1998; Konishi, 1998; Tokumaru and Abe, 2006; Saito et al., 2008a, b; Hayashi and Kitamura, 2010). Use of the native parasitoids in biological control can thus be a promising approach to man-

\footnotetext{
Graduate School of Bioresource and Bioenvironmental Sciences, Kyushu University, Fukuoka, Japan

* Correspondending author (E-mail: ueno@grt.kyushu-u.ac.jp)
}

age Liriomyza pests. Most previous studies have focused on only a few species of native parasitoids, such as Diglyphus isaea, Neochrysocharis formosa and Hemiptarsenus varicornis (Saito et al., 1995; Arakaki and Kinjyo, 1998; Konishi, 1998; Ohno et al., 1999a, b; Ozawa et al., 1999, 2001; Thu and Ueno, 2002; Tran et al., 2007; Ho and Ueno, 2008; Tran and Ueno, 2012; Tran et al., 2012). However, there are still several unfocused native species that may be good biocontrol agents.

Chrysocharis pentheus is a common parasitoid attacking Liriomyza spp. and is widely distributed in the Palaearctic Region including many Asian countries like Japan, Korea, China, and Malaysia (Konishi, 1998; Hayashi and Kitamura, 2010; Chien and Chang, 2013). This parasitoid is abundant in early spring and late autumn when other major leafminer parasitoids are rather scarce (Iguchi, 1997; Mitsuda and Yamasaki, 2003; Hayashi and Kitamura, 2010). Hondo et al. (2006) have also suggested that $C$. pentheus is adapted to low temperature conditions. Thus, C. pentheus may be a useful agent during the period of low temperature conditions. However, very few studies so far have assessed the importance of $C$. pentheus in suppressing leafminer populations and its usefulness as a biological control agent. To evaluate the potential of a certain parasitoid species as a biocontrol agent, it is essential to study its biological characteristics such as development time, adult longevity, fecundity, host range, sex ratio, hostfinding capacity, and host selection behavior (van Driesche and Bellows, Jr., 1996; Jervis, 2005). Such basic information is limited for $C$. pentheus, however.

The objectives of the present study are to investigate biological parameters of the parasitoid. Specifically, 
experiments were conducted to examine the development and offspring sex ratio of $C$. pentheus under low and high temperature conditions. Basing on the results, we will discuss the potential and usefulness of $C$. pentheus in leafminer management.

\section{MATERIALS AND METHODS}

\section{Host and parasitoids}

Seeds of kidney bean were singly planted in plastic pots ( $5.5 \mathrm{~cm}$ in diameter). After around one week of germination, a shallow pan $(32 \mathrm{~cm} * 44 \mathrm{~cm} * 6 \mathrm{~cm})$ containing 24 pots with kidney bean plants was placed on a large shelf covered with a fine meshed nylon. Leafminer adults were released into the shelf for $24 \mathrm{~h}$. After a $24 \mathrm{~h}$ exposure for oviposition, the potted plants were transferred on a different shelf maintained at $25 \pm 1^{\circ} \mathrm{C}$ and 16L:8D. The plants were kept until most leafminer larvae were matured.

Chrysocharis pentheus used in our study was originated from individuals that had emerged from tomato leaves with L. trifolii at the campus of Kyushu University. The culture of $C$. pentheus was maintained on larvae of L. trifolii. Six potted kidney bean plants infested with 3-6 third instars of L. trifolii were introduced into a transparent plastic box $(32 \mathrm{~cm} * 17 \mathrm{~cm} * 25 \mathrm{~cm})$, the upper side of which was covered with a fine meshed nylon. Mated female parasitoids were then introduced into the box. Tissue paper saturated with honey solution was also placed in the box as a food source for the female parasitoids. Female parasitoids were allowed to parasitize leafminer larvae for 24 hours. After 24 hours for parasitism, plants with parasitized hosts were removed from the box, and were kept in the rearing room $\left(25 \pm 1^{\circ} \mathrm{C}, 24 \mathrm{~h}\right.$ light $)$ for 2-6 days. Leaves containing parasitized larvae were then cut off from the plants, and were singly placed in a glass schale ( $9 \mathrm{~cm}$ in diameter) for parasitoid emergence.

\section{Experimental procedures}

A leaf of kidney bean infested with $3-6$ host second and third instars was placed in a glass schale $(9 \mathrm{~cm}$ in diameter). One female $C$. pentheus of 3 days old was introduced into it, and was kept for $24 \mathrm{~h}$ in an incubator maintained at $25 \pm 0.5^{\circ} \mathrm{C}, 16 \mathrm{~L}: 8 \mathrm{D}$. Then, kidney bean leaves were removed from the schale and were observed under a binocular microscope to check whether leafminers had been parasitized. Host paralysis was used to determine parasitism by C. pentheus. Because C. pentheus is a destructive host-feeding parasitoid, hosts used for host-feeding die without producing any parasitoid offspring. To evaluate the exact host suitability for development of $C$. pentheus, we carefully examined whether host larvae had been fed on by female $C$. pentheus or not, and those that had appeared to be used for feeding were discarded. Leaves with parasitized hosts were held in incubators that were maintained at $25 \pm$ $0.5^{\circ} \mathrm{C}$ under $16 \mathrm{~L}: 8 \mathrm{D}$ or $15 \pm 0.5^{\circ} \mathrm{C}$ under $11 \mathrm{~L}: 13 \mathrm{D}$. Parasitized hosts were observed on the daily basis to check the development of the offspring parasitoids. When adult parasitoids were eclosed, the day and the sex of the parasitoids were recorded. The head width of newly eclosed parasitoids was measured under a binocular microscope, as an index of the size.

The data were analyzed with JMP (2010). The distributions of development time and wasp size were fitted to normal distributions before the statistical treatments, and parametric procedures were then applied to analyze statistical differences. The offspring survival and sex ratio were analyzed with multiple logistic regression analyses in which temperature and host instar were included as independent variables.

\section{RESULTS}

A laboratory culture of $C$. pentheus was successfully established using L. trifolii as a host. The parasitoid was easily reared in the laboratory using the rearing procedure that was basically the same with $H$. varicornis $-L$. trifolii system (Thu and Ueno, 2002). The following experiments were undertaken with laboratory-reared parasitoids.

In all, 346 host larvae were parasitized by female $C$. pentheus in the experiment, and 147 and 199 parasitized larvae were reared at $15^{\circ} \mathrm{C}$ and $25^{\circ} \mathrm{C}$, respectively. Laboratory rearing demonstrated that $C$. pentheus developed successfully on larvae of $L$. trifolii. A multiple logistic regression analysis showed that temperatures significantly affected the likelihood of successful development to adulthood whereas host instars $\left(2^{\text {nd }}\right.$ versus $3^{\text {rd }}$ larval instars of L. trifolii) did not (Table 1). The percentages of successful development, measured as the percentages of hosts that had produced parasitoid adults, were $63.9 \%$ and $89.4 \%$ at $15^{\circ} \mathrm{C}$ and $25^{\circ} \mathrm{C}$, respectively, when data were combined for host instars (Figure 1).

The mortality of developing parasitoids mostly occurred at larval stages, and $34.7 \%$ of individuals died before pupation at $15^{\circ} \mathrm{C}$ whereas only $3.0 \%$ did so at $25^{\circ} \mathrm{C}$. The difference was highly significant (chi-squared test; $\left.x^{2}=66.0, P<0.0001\right)$. The mortality during the pupal stage was low $\left(3.4 \%\right.$ at $15^{\circ} \mathrm{C}$ and $7.5 \%$ at $\left.25^{\circ} \mathrm{C}\right)$ and did not significantly differ between the temperature groups (chi-squared test; $x^{2}=2.81, P=0.094$ ).

The mean development times from egg to adult eclosion were summarized in Table 2. Temperature had a strong influence to development, and wasps eclosed around 2 weeks after parasitization at $25^{\circ} \mathrm{C}$ and 1 month at $15^{\circ} \mathrm{C}$. Statistical results based on a three-way ANOVA showed that host instars did not affect developmental time whereas wasp sex and temperature had significant

Table 1. A multiple logistic regression analysis to assess the effect of temperature and host instar on the survival of parasitoid offspring

\begin{tabular}{ccc}
\hline Factors & $x^{2}$ values & $P$ values \\
\hline Temperature & 32.5 & $<0.0001$ \\
Host instar & 0.49 & 0.48 \\
\hline
\end{tabular}

Whole model was highly significant $(P<0.0001)$.

Interaction between the two factors was not significant. 
Table 2. Developmental time in days of Chrysocharis pentheus reared on Liriomyza trifolii

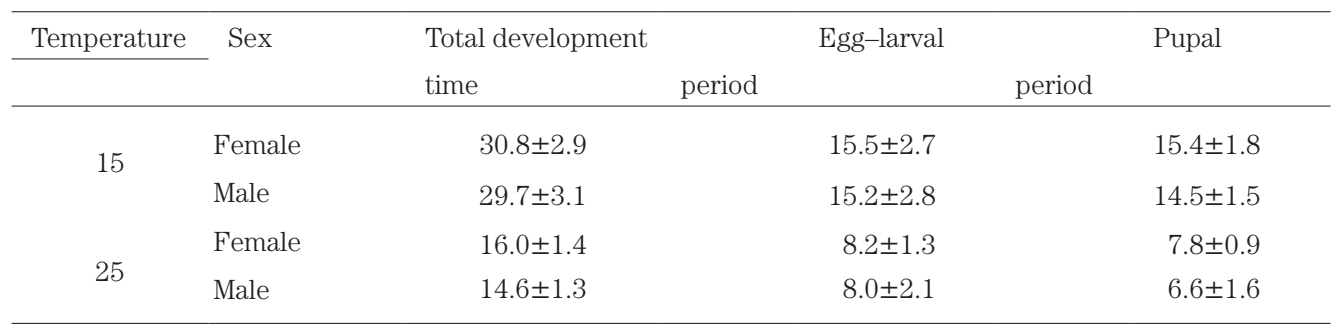

See also Table 3 for the statistical results.

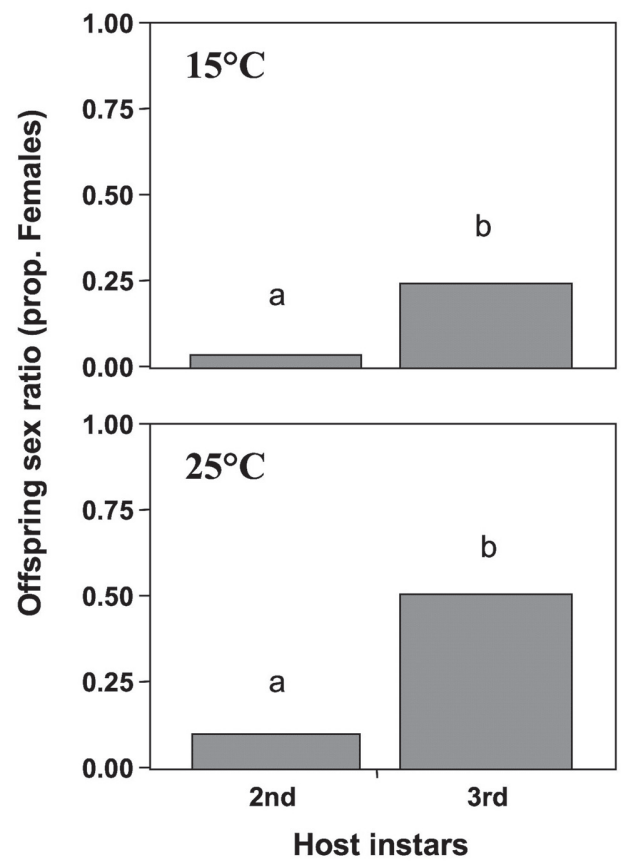

Fig. 1. Effect of temperature $\left(15^{\circ} \mathrm{C}\right.$ versus $\left.25^{\circ} \mathrm{C}\right)$ on the survival of offspring C. pentheus (= proportion of hosts producing parasitoid offspring). Different letters above bars show a significant difference between the groups (chi-squared test; $P<0.0001$ ). See also Table 1 for the statistical result

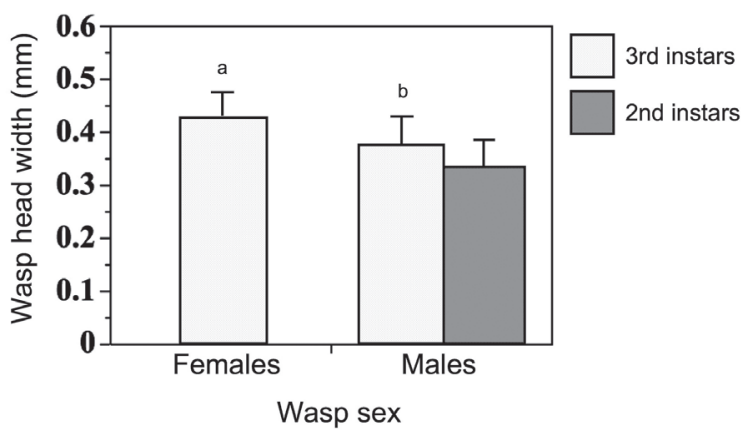

Fig. 2. Offspring sex ratio at the time of wasp emergence in relation to host instars at two different rearing conditions (above; $15^{\circ} \mathrm{C}$, below; $25^{\circ} \mathrm{C}$ ). Different letters above bars show a significant difference between the groups (chisquared test; $P<0.05)$. See also Table 4 for the statistical result.
Table 3. The results of three-way ANOVA for factors affecting development time of $C$. pentheus (from egg to adult eclosion)

\begin{tabular}{lcc}
\hline \multicolumn{1}{c}{ Factors } & $t$ values & $P$ values \\
\hline Total development time & & \\
Temperature & 54.08 & $<0.0001$ \\
Sex & 3.85 & 0.0001 \\
Host instar & -0.75 & 0.45 \\
Egg-larval period & & \\
Temperature & 24.85 & $<0.0001$ \\
Sex & 0.41 & 0.69 \\
Host instar & -0.53 & 0.60 \\
Pupal period & & \\
Temperature & 40.73 & $<0.0001$ \\
Sex & 5.00 & $<0.0001$ \\
Host instar & -0.27 & 0.78 \\
\hline
\end{tabular}

Whole models were highly significant $(P<0.0001)$. Interactions were not significant and were hence excluded from the analyses.

Table 4. The result of a multiple logistic regression analysis for wasp sexes emerging from second versus third host instars at two different temperature conditions

\begin{tabular}{ccc}
\hline Factors & $x^{2}$ values & $P$ values \\
\hline Temperature & 13.50 & 0.0002 \\
Host instar & 36.33 & $<0.0001$ \\
\hline
\end{tabular}

Whole model was highly significant $(P<0.0001)$. Interaction was not significant and was hence excluded from the analysis.

Table 5. The result of a two-way ANOVA for wasp size (head width) in relation to wasp sex and host instars

\begin{tabular}{ccc}
\hline Factors & $t$ values & $P$ values \\
\hline Wasp sex & 4.21 & $<0.0001$ \\
Host instar & -2.85 & 0.0056 \\
Development time & -1.55 & 0.126 \\
\hline
\end{tabular}

Whole model was highly significant $(P<0.0001)$. Interaction was not significant and was hence excluded from the analysis. 


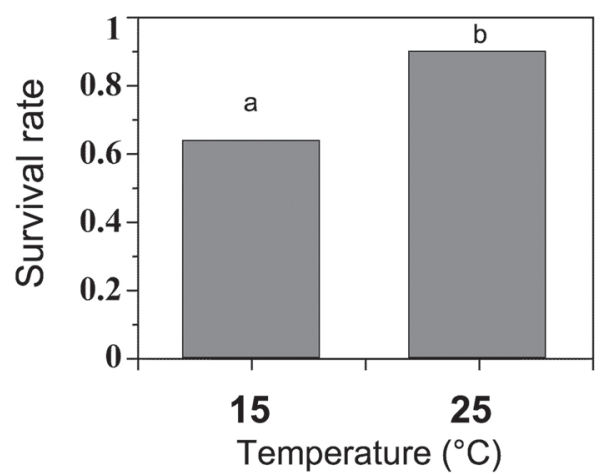

Fig. 3. The size of $C$. pentheus emerging in relation to wasp sex. Different letters above bars show a significant difference between the groups (one-way ANOVA; $P<0.0001$ ). For data from second instars, the size of females is not shown because only one female individual emerged from host $2^{\text {nd }}$ instar. See also Table 5 for the statistical result.

impacts (Table 3). Males developed significantly but slightly faster than females did (Tables 2). Curiously, development time during the larval stage did not differ between the sexes but the sexual difference in time appeared during the pupal stage (Table 3 ).

The offspring sex ratio at the time of wasp eclosion differed depending on host instars and temperatures (Table 4). The third instars of L. trifolii produced significantly more female parasitoids than the second instars did, regardless of temperature conditions (Figure 2). However, the proportion of female C. pentheus produced was much lower at $15^{\circ} \mathrm{C}$ than $25^{\circ} \mathrm{C}$ (Figure 2).

The size of $C$. pentheus was measured for 91 individuals reared at $15^{\circ} \mathrm{C}$. The head width as an index of wasp size was significantly affected by wasp sex and host instars (Table 5). Basically, wasp size was larger in females than males (Figure 3). Host third instars produced larger $C$. pentheus than second instars did though comparison was not possible for females because only one individual was produced from second host instar (Figure 3)

\section{DISCUSSION}

The present study shows that Chrysocharis pentheus can easily be maintained in the laboratory with rearing procedures used for other eulophid parasitoids of dipteran leafminers such as Hemiptarsenus varicornis, Diglyphus isaea and Neochrysocharis formosa (e.g., Thu and Ueno, 2002; Tran et al., 2007). When L. trifolii was used as a host of $C$. pentheus at $25^{\circ} \mathrm{C}$, the percentage of hosts successfully producing parasitoid offspring was nearly $90 \%$, indicating that $L$. trifolii is a suitable host for $C$. pentheus. This might be somewhat curious because the leafminer $L$. trifolii is an exotic species while C. pentheus is native to Japan. Chrysocharis pentheus has been recorded from a variety of dipteran leafminers belonging to the genera Liriomyza,
Phytomyza and Chromatomyia (e.g., Sugimoto and Ishii, 1979; Sugimoto et al., 1982; Iguchi, 1997; Konishi, 1998; Tokumaru and Abe, 2006; Saito et al., 2008a, b). In addition, this parasitoid is able to use a lepidopteran leafminer, Phyllocnistis citrella (the citrus leafminer) as host (Mafi and Ohbayashi, 2004). Hence, the polyphagous nature will enable $C$. pentheus to parasitize and develop on a wide range of different leafmining hosts. This parasitoid thus should have a potential to use exotic Liriomyza species as host.

At a low temperature condition of $15^{\circ} \mathrm{C}$, the survival of $C$. pentheus was reduced to around $60 \%$. Mortality during the larval stage caused the reduced survival. Although C. pentheus is rather cold tolerant (Hondo et al., 2006), the likelihood of larval mortality may increase under low temperatures. Alternatively, larval survival is reduced because the quality of leaf containing parasitized leafminers is lowered during a relatively long period of rearing (around one month in our study) and because leaf of lowered quality does not provide a suitable microenvironment for the developing $C$. pentheus within the mine of host.

It is noticeable that $C$. pentheus develops to adult even under the low temperature/short day condition of $15^{\circ} \mathrm{C} / 11 \mathrm{~L}: 13 \mathrm{D}$. With this condition, insects of the temperate region would undergo diapause to survive winter (Tauber et al., 1986). It is unknown what development stage $C$. pentheus undergo diapause. However, the present result does suggest that adult $C$. pentheus occur in late autumn and early spring. Previous studies in fact have demonstrated that high levels of parasitism by $C$. pentheus are detected in late autumn and early spring when other leafminer parasitoids are rather scarce (Iguchi, 1997; Mitsuda and Yamasaki, 2003).

Neochrysocharis formosa, which is also a leafminer eulophid parasitoid with a southern distribution, requires 1.5 months from oviposition to adult emergence (Hondo et al., 2006) while C. pentheus finished the development around one month (Table 2). Relatively fast development at $15^{\circ} \mathrm{C}$ in $C$. pentheus suggests that this parasitoid is adapted to cool environments. Indeed, Hondo et al. (2006), who compared thermal tolerance of eight native parasitoids of dipteran leafminers, demonstrated that $C$. pentheus is adapted to low temperatures. Curiously, $C$. pubicornis, a related species of $C$. pentheus, undergoes summer diapause; the adults terminate the diapause and emerge under low temperature conditions (Baeza Larios et al., 2007). Chrysocharis pentheus may be useful for biological control during growing seasons between autumn and early spring.

In general, host size or instar affects the survival of developing parasitoids; parasitoid survival is mostly lower in smaller hosts or younger host instars (Vinson and Iwantsch, 1980; Godfray, 1994; Ueno, 1999). In the present study, we did not detect such an effect at least between host second and third instars. The host L. trifolii appears suitable for development of $C$. pentheus, regardless of the host stage.

Sexual difference in size is common among parasitoids including leafminer eulophids, and a consistent pat- 
tern is that females are larger than males (Bordat et al., 1995; Ode and Heinz, 2002; Bazzocchi et al., 2003). This was the case for $C$. pentheus in the present study. In general, larger host leafminers produce larger eulophid parasitoids (Croft and Copland, 1995; Ode and Heinz, 2002; Salvo and Valladares, 2002). Because female eggs are more likely to be laid on larger hosts in eulophids (Heinz and Parrella, 1990; Ode and Heinz, 2002), sexual difference in size should result, at least in part, from a difference in host size used for male versus female offspring.

For most of parasitoids examined so far, the development time of males is shorter than that of females (Ueno and Tanaka, 1994; Quicke, 1997). Similarly, in $C$. pentheus, males developed faster than females. This sexual difference arose during the pupal stage, not during the larval stage. It is not known why such a sexual difference emerges during the pupal stage.

The sex ratio of parasitoid wasps is variable in response to host-associated factors such as host size, age, stage and prior parasitism, and host size is one of the major factors influencing parasitoid sex ratio (King, 1987; Godfray, 1994; Ueno, 1999; Ode and Heinz, 2002; Ueno, 2015). In the present study, host third instars yielded more female $C$. pentheus than second instars. Because the former host larvae are much larger than the latter, the difference in size between the two host instars is considered responsible for the difference in observed sex ratio. Similar results are obtained for other leafminer parasitoids, and host-size dependent sex ratio may be a general rule for leafminer parasitoids (Croft and Copland, 1995; Ode and Heinz, 2002; Chow and Heinz, 2005, 2006).

In addition, physical factors such as temperature and humidity may influence parasitoid sex ratio (King, 1987). In C. pentheus, temperatures affected the offspring sex ratio. Production of fewer female offspring under lower temperatures has not been recorded for leafminer parasitoids so far. How low temperatures affect the parasitoid sex ratio is not clear. A likely explanation is that the survival of immature females is lower at lower temperatures. In fact, the overall survival of $C$. pentheus was lower at $15^{\circ} \mathrm{C}$ than $25^{\circ} \mathrm{C}$. Sex-dependent mortality in response to temperature is not confirmed in any parasitoids, but this should be examined in the future study.

Curiously, the sex ratio of $C$. pentheus is biased toward males. Male-biased sex ratio is often reported for a number of parasitoid wasps including leafminer parasitoids used for biological control (Ode and Heinz, 2002; Chow and Heinz 2005, 2006). It is not known why the sex ratio of $C$. pentheus is male-biased. Because malebiased sex ratio results in low efficiency of mass production of the parasitoid, the future study also should address this question to improve the sex ratio.

\section{REFERENCES}

Arakaki, N. and K. Kinjo 1998 Notes on the parasitoid fauna of the serpentine leafminer Liriomyza trifolii (Burgess) (Diptera: Agromyzidae) in Okinawa, southern Japan. Appl. Entomol.
Zool., 33: 577-581

Baeza Larios, G., K. Ohno and F. Fukuhara 2007 Effects of photoperiod and temperature on preimaginal development and summer diapause of Chrysocharis pubicornis (Zetterstedt) (Hymenoptera: Eulophidae), a pupal parasitoid of leafminers (Diptera: Agromyzidae). Appl. Entomol. Zool., 42: 189-197

Bazzocchi, G. G., A. Lanzoni, G. Burgio and M. R. Fiacconi 2003 Effects of temperature and host on the pre-imaginal development of the parasitoid Diglyphus isaea (Hymenoptera: Eulophidae). Biol. Cont., 26: 74-82

Bordat, D., E. V. Coly and C. Roux-Olivera 1995 Morphometric, biological and behavioral differences between Hemiptarsenus varicornis (Hym., Eulophidae) and Opius dissitus (Hym. Braconidae) parasitoids of Liriomyza trifolii (Dip., Agromyzidae). J. Appl. Entomol., 119: 423-427

Chien, C-C. and S-C. Chang 2013 Effect of Temperature on killing of Liriomyza huidobrensis (Diptera: Agromyzidae) by the parasitoids Chrysocharis pentheus and Closterocerus okazakii (Hymenoptera: Eulophidae). J. Taiwan Agric. Res. 62: $71-82$

Chow, A. and K. M. Heinz 2005 Using hosts of mixed sizes to reduce male-biased sex ratio in the parasitoid wasp, Diglyphus isaea. Entomol. Exp. Appl., 117: 193-199

Chow, A. and K. M. Heinz 2006 Control of Liriomyza langei on chrysanthemum by Diglyphus isaea produced with a standard or modified parasitoid rearing technique. J. Appl. Entomol., 130: 113-121

Croft, P. and M. J. W. Copland 1995 The effect of host instar on the size and sex-ratio of the endoparasitoid Dacnusa sibirica. Entomol. Exp. Appl., 74: 121-124

Foba, C. N., D. Salifu, Z. O. Lagat, K. S. Akutse and K. K. M. Fiaboe 2015 Species composition, distribution, and seasonal abundance of Liriomyza leafminers under different vegetable production systems and agroecological zones in Kenya. Env. Entomol., 44: 223-232

Godfray, H. C. J. 1994 Parasitoids: Behavioral and Evolutionary Ecology. Princeton University Press, New Jersey

Gratton, C. and S. C. Welter 2001 Parasitism of Natural Populations of Liriomyza helianthi Spencer and Calycomyza platyptera (Thomson) (Diptera: Agromyzidae). Biol. Cont., 22: $81-97$

Guantai, M. M., C. P. K. O. Ogol, D. Salifu, K. S. Akutse and K. K. M. Fiaboe 2015 Differential effects of pesticide applications on Liriomyza huidobrensis (Diptera: Agromyzidae) and its parasitoids on pea in Central Kenya. J. Econ. Entomol., 108 662-671

Hayashi, Y. and K. Kitamura 2010 Parasitoid complex and seasonal occurrence of Chromatomyia horticola (Goureau) in Matsue, Shimane Prefecture. Hoshizaki Gurin Zaidan Kenkyu Hokoku, 13: 1-13

Heinz, K. M. and M. P. Parrella 1990 Holarctic distribution of the leafminer parasitoid Diglyphus begini (Hymenoptera: Eulophidae) and notes on its life history attacking Liriomyza trifolii (Diptera: Agromyzidae) in Chrysanthemum. Ann. Entomol. Soc. Am., 88: 916-924

Ho, T. T. G. and T. Ueno 2008 Host discrimination and factors affecting incidence of superparasitism in Hemiptarsenus varicornis (Hymenoptera: Eulophidae), a parasitoid of the leafminer Liriomyza trifolii (Diptera: Agromyzidae). J. Fac. Agr., Kyushu Univ., 53: 447-452

Ho, T. T. G. and T. Ueno 2011 The effects of honey as a dietary supplement on the survivorship and nutrition-storing capacity of Hemiptarsenus varicornis (Hymenoptera: Eulophidae), a parasitoid of Liriomyza (Diptera: Agromyzidae) leafmiiners. Int. J. Trop. Insect Sci., 31: 78-84

Hondo, T., A. Koike and T. Sugimoto 2006 Comparison of thermal tolerance of seven native species of parasitoids (Hymenoptera: Eulophidae) as biological control agents against Liriomyza trifolii (Diptera: Agromyzidae) in Japan. Appl. Entomol. Zool., 41: 73-82

Iguchi, M. 1997 Suppression of Liriomyza trifolii by native parasitoids in mini-tomato. Kongetsu no Nogyo 41: 64-68 (in 
Japanese)

Jervis, M. A. 2005 Insects as Natural Enemies: A Practical Perspective. Springer, Dordrecht

JMP 2010 JMP version 8.0. SAS Institute Inc., Cary, North Carolina

King, B. H. 1987 Offspring sex ratios in parasitoid wasps. Q. Rev. Biol., 62: 367-396

Konishi, K. 1998 An illustrated key to the hymenopterous parasitoids of Liriomyza trifolii in Japan. Miscellaneous Publication of the National Institute of Agro-environmental Science 22: 27-76 (In Japanese)

Liu, T-X., K. Kang, K. M. Heinz and J. Trumble 2009 Biological control of Liriomyza leafminers: progress and perspective. CAB Reviews 4. Available at: http://www.cababstractsplus.org/ cabreviews

Mafi, S. A. and N. Ohbayashi 2004 Seasonal prevalence of the citrus leafminer, Phyllocnistis citrella Stainton (Lepidoptera: Gracillariidae) and its parasitoids in controlled and uncontrolled Citrus iyo grooves in Ehime Prefecture, Japan. Appl. Entomol. Zool., 39: 597-601

Matsuda, K. and T. Saito 2014 Insecticide susceptibility and carboxylesterase activity in leafminers (Diptera: Agromyzidae) and their associated hymenopteran parasitoids. Crop Prot., 55: $50-54$

Minkenberg, O. P. J. M. and J. C. van Lenteren 1986 The leafminer Liriomyza bryoniae and L. trifolii (Diptera: Agromyzidae), their parasites and host plants: A review. Agr. Univ., Wageningen Paper, 86: 1-50

Mitsuda, K. and Y. Yamasaki 2003 Parasitoid complex Serpentine leaf miner (Liriomyza trifolii (Burgess)) in Ehime Prefecture. Ehime Pref. Agr. Exp. Stat. Rep., 37: 35-39

Ode, P. J. and Heinz K. 2002 Host-size-dependent sex ratio theory and improving mass-reared parasitoid sex ratios. Biol. Cont., 24: $31-41$

Ohno, K, T. Ohmori and H. Takemoto 1999a Effect of insecticide applications and indigenous parasitoids on population trends of Liriomyza trifolii in gerbera greenhouses. Jap. J. Appl. Entomol. Zool, 43: 81-86

Ohno, K., K. Takesaki, D. Yamaguchi and H. Takemoto 1999b Effects of milbemectin acaricide on mortality rate of agromyzid leafminer, Liriomyza trifolii (Burgess), and its larval parasitoid, Diglyphus isaea (Walker) (Hymenoptera : Eulophidae). Jap. J. Appl. Entomol. Zool., 43: 93-97 (in Japanese with English summary)

Ozawa, A, Saito T. and F. Ikeda 1998 Effects of pesticides on Diglyphus isaea (Walker) and Dacnusa sibirica Telenga, parasitoids of Liriomyza trifolii (Burgess). Jap. J. Appl. Entomol. Zool., 42: 149-161 (in Japanese with English summary)

Ozawa, A., T. Saito and M. Ota 1999 Biological control of American serpentine leafminer, Liriomyza trifolii (Burgess), on tomato in greenhouses by parasitoids I. Evaluation of biological control by release of Diglyphus isaea (W9alker) in experimental greenhouses. Jap. J. Appl. Entomol. Zool., 43: $161-168$

Ozawa, A., T. Saito and M. Ota 2001 Biological control of the American serpentine leafminer, Liriomyza trifolii (Burgess), on tomato in greenhouses by parasitoids II. Evaluation of biological control by Diglyphus isaea (Walker) and Dacnusa sibirica Telenga in commercial greenhouses. Jap. J. Appl. Entomol. Zool., 45: 61-74 (in Japanese with English summary)

Parrella, M. P. 1987 Biology of Liriomyza. Ann. Rev. Entomol., 32: 201-224

Parrella, M. P., V. P. Jones and G. D. Christie 1987 Feasibility of parasites for biological control of Liriomyza trifolii (Diptera: Agromyzidae) on commercially grown chrysanthemum. Env. Entomol., 16: 832-837

Quicke, D. L. J. 1997 Parasitic Wasps. Chapman and Hall, London

Rauf, A., B. M. Shepard and M. W. Johnson 2000 Leafminers in vegetables, ornamental plants and weeds in Indonesia: Surveys of host crops, species composition and parasitoids. Inter. $J$ Pest Manage., 46: 257-266

Saito, T., A. Ozawa and F. Ikeda 1995 The evaluation of two imported hymenopteran parasites as biological control agents for the serpentine leafminer, Liriomyza trifolii (Burgess) Proc. Kanto Plant Prot. Soc., 42: 235-237 (in Japanese)

Saito, T., M. Doi, Y. Tagami and K. Sugiyama 2008a Hymenopterous parasitoids of the exotic leafminers Liriomyza trifolii (Burgess) Liriomyza sativae Blanchard (Diptera: Agromyzidae) in Shizuoka Prefecture, Japan. Jap. J. Appl. Entomol. Zool., 52: 225-229 (in Japanese with English summary)

Saito, T., M. Doi, H. Katayama, S. Kaneko, Y. Tagami and K. Sugiyama 2008b Seasonal abundance of hymenopteran parasitoids of the leafminer Chromatomyia horticola (Diptera: Agromyzidae) and the impact of insecticide applications on parasitoids in garden pea field. Appl. Entomol. Zool., 43: 617-624

Salvo, A. and G. Valladares 2002 Plant-related intraspecific size variation in parasitoids (Hymenoptera: Parasitica) of a polyphagous leafminer (Diptera : Agromyzidae). Env. Entomol. 31: $874-879$

Salvo, A., M. S. Fenoglio and M. Videla 2005 Parasitism of a leafminer in managed versus natural habitats. Agr. Ecosys. Env. 109: $213-220$

Saryazdi, G. A., M. J. Hejazi, M. R. Rashidi and S. Ferguson 2014 Incidence and characterization of resistance to Fenpropathrin in som Liriomyza sativae populations in Iran. J. Econ. Entomol., 107: 1908-1915

Spencer, K. A. 1989 Leafminer. In "Plant Protection and Quarantine Vol II. Selected Pests and Pathogens of Quarantine Significant", CRC Press, Inc., Boca Raton, Florida, USA, pp $77-98$

Sugimoto, T. and M. Ishii 1979 Mortality of larvae of a ranunculus leaf mining fly, Phytomyza ranunculi (Diptera : Agromyzidae), due to parasitization and host-feeding by its eulophid parasite, Chrysocharis pentheus (Hymenoptera: Eulophidae). Appl. Entomol. Zool., 14: 410-418

Sugimoto, T., I. Yasuda, M. Ono and S. Matsunaga 1982 Occurrence of a ranunculus leaf-mining fly, Phytomyza ranunculi and its eulophid parasitoids from fall to summer in the low land. Appl. Entomol. Zool., 17: 139-143

Tauber, M. J., C. A. Tauber and S. Masaki 1986 Seasonal adaptations of insects. Oxford Univ. Press, New York

Thu, G. H. T. and T. Ueno 2002 Biology of Hemiptarsenus varicornis (Hymenoptera: Eulophidae), a parasitoid wasp of the leafminer Liriomyza trifolii (Diptera: Agromyzidae). J. Fac. Agr., Kyushu Univ., 47: 45-54

Tokumaru, S. and Y. Abe 2006 Hymenopterous parasitoids of leafminers, Liriomyza sativae Blanchard, L. trifolii (Burgess), and L. bryoniae (Kaltenbach) in Kyoto Prefecture. Jap. J. Appl. Entomol. Zool., 50: 341-345 (in Japanese with English summary)

Tran, D. H., T. Ueno and M. Takagi 2007 Comparison of the suitability of Liriomyza chinensis and L. trifolii (Diptera: Agromyzidae) as hosts for Neochrysocharis okazakii (Hymenoptera: Eulophidae). Biol. Cont., 41: 354-360

Tran, D. H. and T. Ueno 2012 Toxicity of insecticides to Neochrysocharis okazakii, a parasitoid of Liriomyza leafminers on vegetables. J. Fac. Agr., Kyushu Univ., 57: 127-131

Tran, D. H., K. P. Le, T. Ueno and M. Takagi 2012 Effects of temperature and host on the immature development of the parasitoid Neochrysocharis okazakii (Hymenoptera: Eulophidae). J. Fac. Agr, Kyushu Univ., 57: 133-137

Ueno, T. 1999 Host-size-dependent sex ratio in a parasitoid wasp. Res. Popul. Ecol., 41: 47-57

Ueno, T. 2006 Current status of insect pests attacking green bunching onion in central and southern Vietnam. J. Fac. Agr., Kyushu Univ., 51: 275-283

Ueno, T. 2015 Unexpected use of pupal stage of a Lepidopteran host by the ectoparasitoid wasp Agrothereutes lanceolatus (Hymenoptera: Ichneumonidae). Entomol. Ornithol. Herpetol., : : 140. doi:10.4172/2161-0983.1000140 
Ueno, T. and T. Tanaka 1994 Comparative biology of six polyphagous solitary pupal endoparasitoids (Hymenoptera: Ichneumonidae): differential host suitability and sex allocation. Ann. Entomol. Soc. Am., 87: 592-598

van Driesche, R. G. and T. S. Bellows, Jr 1996 Biological Control. Chapman and Hall, New York

Vinson, S. B. and G. F. Iwantsch 1980 Host suitability for insect parasitoids. Ann. Rev. Entomol., 25: 397-419

Wardlow, L. R. 1985 Control of leafminer on Chrysanthemums and tomatoes by parasites. In "Biological Pest Control: the
Glasshouse Experience", Cornell Univ. Press, Ithaca, New York, pp. 129-133

Weintraub, P. G. 2001 Effects of cyromazine and abamectin on the leafminer, Liriomyza huidobrensis and its parasitoid, Diglyphus isaea in potatoes. Crop Prot. 20: 207-213

Weintraub, P. G. and A. R. Horowitz 1998 Effects of translaminar versus conventional insecticides on Liriomyza huidobrensis (Blanchard) (Diptera: Agromyzidae) and Diglyphus isaea Walker (Hymenoptera: Eulophidae) populations in celery. J. Econ. Entomol., 91: 1180-1185 